\title{
Comment: quicker trial of void after midurethral sling procedure many not lead to earlier discharge times
}

\author{
Alexandra Mowat ${ }^{1}$ (D) $\cdot$ Malcolm Frazer ${ }^{2}$ \\ Received: 14 January 2018 / Accepted: 16 February 2018 / Published online: 19 March 2018 \\ (C) The International Urogynecological Association 2018
}

\section{Dear Editor,}

We congratulate Myers et al. [1] on a well-designed study comparing two methods for trial of void after a midurethral sling procedure. The trial was aimed at assessing whether a retrograde fill in the operating theatre, as opposed to in recovery, would decrease the time spent in recovery before patients went home.

We read the results with interest: initiating the trial of void in the operating theatre decreased the time taken to complete a successful trial but did not decrease the time until discharge. We recently had a similar randomised controlled trial accepted for publication in the Australian and New Zealand Journal of Obstetrics and Gynaecology [2] that compared the retrograde fill initiated in the operating theatre with our hospital's standard auto-fill trial. In our Australian hospital setting, it is common for women to stay overnight after a midurethral sling procedure, often due to the length of time taken to pass the trial of void. We designed a study aimed at establishing whether a retrogradefill trial of void would result in more patients being discharged from recovery on the day of surgery. In keeping with the results of Myers et al. [1], we found that a retrograde-fill trial of void decreased the time it takes to

Alexandra Mowat

zanhmowat@gmail.com

Malcolm Frazer

frazers5@bigpond.com

1 Greenslopes Private Hospital and Royal Brisbane and Women's Hospital, University of Queensland, Brisbane, Australia

2 Gold Coast University Hospital and Pindara Private Hospital, Benowa, Australia pass the trial but did not result in more same-day discharges. In their discussion, Myers et al. suggested that there are likely to be several factors contributing to patients remaining in recovery despite passing their trial of void. Certainly in our study, we concluded that both nursing and patient expectations were significant contributing factors to this phenomenon. In our hospital setting, both patients and nurses generally expected patients to have an overnight admission, and we found that this expectation was difficult to override despite preoperation counselling.

\section{Compliance with ethical standards}

Conflicts of interest None.

\section{References}

1. Myers EM, Matthews CA, Crane AK, Connolly A, Wu JM, Geller EJ. Two techniques for assessing postoperative voiding function, a randomized trial. Int Urogynecol. 2017;28(10):1567-72.

2. Mowat A, Brown B, Pelecanos A, Mowat V, Frazer M. Infusion-fill method versus standard auto-fill trial of void protocol following a TVT-exact procedure: a randomized controlled trial (ANZJOG2017-0260.R1). 